ECCOMAS

Proceedia
COMPDYN 2021

$8^{\text {th }}$ ECCOMAS Thematic Conference on Computational Methods in Structural Dynamics and Earthquake Engineering

M. Papadrakakis, M. Fragiadakis (eds.)

\title{
SEISMIC LOSS ANALYSIS OF A CODE-DESIGNED INFILLED RC BUILDING ACCOUNTING FOR INFILL MODEL CLASS UNCERTAINTY
}

\author{
Fabio Romano ${ }^{1}$, Mohammad S. Alam ${ }^{2}$, Maria Zucconi ${ }^{1}$, Marco Faggella ${ }^{3,4}$, Andre Bar- \\ bosa $^{2,5}$, Barbara Ferracuti ${ }^{1}$ \\ ${ }^{1}$ Niccolò Cusano University, Via Don Carlo Gnocchi 3, Rome, Italy \\ \{fabio.romano, maria.zucconi, barbara.ferracuti\}@unicusano.it \\ ${ }^{2}$ Oregon State University, 101 Kearney Hall, Corvallis, OR 97331, USA \\ \{alammo,andre.barbosa\}@oregonstate.edu \\ ${ }^{3}$ Sapienza University of Rome, Via Eudossiana 18, Rome, Italy \\ ${ }^{4}$ University of Porto, 4200-465, Porto, Portugal \\ mfaggella@gmail.com \\ ${ }^{5}$ University of Bristol, Queen's Building, University Walk, Bristol, BS8 1TR, UK \\ andre.barbosa@bristol.ac.uk
}

\begin{abstract}
Several sources of uncertainty affect seismic loss analysis results, and investigating their influence is crucial to obtain reliable quantitative estimates of the building performance under seismic excitations. The present study propagates uncertainties from seismic hazard to annualized seismic losses of a code-designed unreinforced masonry infilled reinforced concrete moment resisting frame building. Uncertainties were considered in the ground motion record-to-record variability and in model class uncertainty of masonry infill walls that originates from two equivalent strut macro-model classes used and uncertainties in their backbone model parameters. A large set of finite element models (FEMs) was generated for each infill strut model class by Latin hypercube sampling (LHS) of the statistical distribution of experimentally fitted backbone parameters. Each finite element model was subjected to multiple-stripe based nonlinear response history analyses to estimate the structural response parameters of interest. The propagation of uncertainties from structural response to repair costs was evaluated considering mean values and dispersion in repair cost at the selected seismic hazard levels for two building performance models. Moreover, the contribution of different structural and non-structural elements of the studied building to the expected annualized losses was evaluated.
\end{abstract}

Keywords: expected annual losses; FEMA P-58; model class uncertainty; seismic risk analysis; URM infill. 


\section{INTRODUCTION}

Reinforced concrete (RC) moment-resisting frames with unreinforced masonry (URM) infills represent a predominant typology of buildings worldwide. Understanding the performance of such building typology to seismic actions is crucial to assess the impact of their potential damage on the economic and societal losses [1-6]. To this end, performance-based earthquake engineering (PBEE) methods and tools can be used to evaluate the seismic risk of existing or newly designed structures through targeted seismic loss analysis. Seismic loss analysis is a very complex process, whereby a robust assessment of the seismic performance is needed and requires propagation of relevant sources of uncertainty [7]. In particular, uncertainties in numerical modeling of structural and non-structural elements and damage mechanisms considerably affect the seismic response, such as those related to the modeling of infill panels. Even though, several research efforts addressed the effect of modeling parameter uncertainty of URM infill walls on the seismic structural response of RC buildings [8-10], only a limited number of studies focused on the impact of model class uncertainty on estimated losses. Model class uncertainty $[11,12]$ incorporates the uncertainty in modeling parameters and the uncertainty in the selection of appropriate models to describe a general physical phenomenon.

This paper deals with the impact of incorporating model class uncertainty related to URM infills on seismic loss assessment results. Model class uncertainty is described via two equivalent infill strut models and considering the uncertainty in their backbone parameters by generating 200 realizations of the infill strut backbone for each infill model. Nonlinear response history analyses (NRHAs) were carried out using the multiple-stripe analysis (MSA) approach [13], with a different set of 30 ground motion (GM) records selected for each seismic intensity level. The FEMA P-58 methodology [14], which finds several applications in the literature for building-specific seismic loss analyses $[15,16]$, was adopted to evaluate the monetary performance of the considered building. This was achieved through the building performance models developed incorporating the NRHAs results of the two selected infill model classes and considering necessary information on elements damage and loss characteristics. In particular, the recently validated SP3 web-tool [17] has been used for the seismic loss analysis. Results highlight the impact of model class uncertainty for URM walls by comparing mean repair costs and mean annualized costs obtained for the two selected model classes.

\section{DESCRIPTION OF BUILDING}

An existing code-conforming RC URM building is selected to evaluate the effect of infillstrut model class uncertainty on seismic loss assessment. The building is an irregular six-story structure infilled with URM walls, with three bays in the Y-direction (transverse) and five bays in the X-direction (longitudinal), as shown in Figure 1(a). The lateral force resisting system consists of RC special moment-resisting frames in both longitudinal and transverse directions. The concrete used has expected compressive strength of $f_{c e}^{\prime}=30 \mathrm{MPa}$, and the reinforcing steel with expected yield strength of $f_{y}=496 \mathrm{MPa}$. Figure 1 (b) shows the elevation view of the internal frames for grid lines B to E, where infill walls are used as partitions in second and third stories. Solid clay bricks are used for infill wall panels. Detailed information regarding the building description is reported in [18]. 

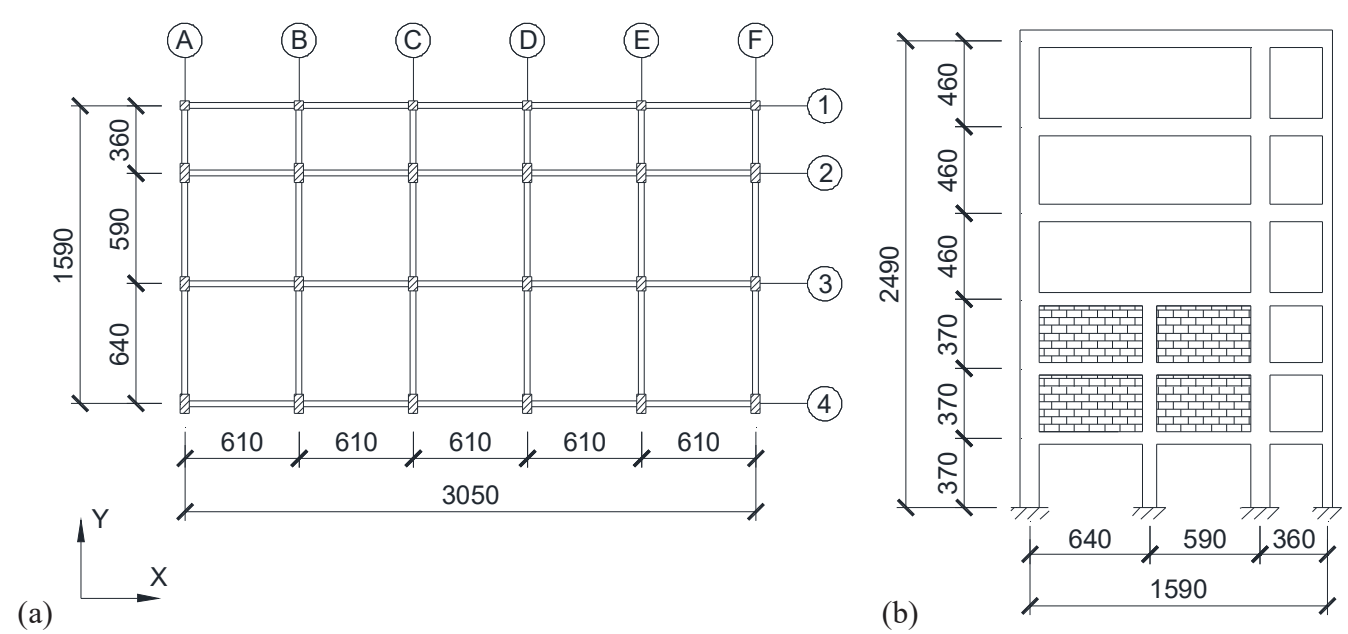

Figure 1: Code-designed infilled RC URM building: (a) second-story plan view of structural RC frames, (b) elevation view along Y-direction (transverse direction) of internal frames, (dimensions in $\mathrm{cm}$ ).

\section{NUMERICAL MODELING AND STRUCTURAL ANALYSIS}

\subsection{RC frame and infill strut modeling}

A two-dimensional model of the building internal $\mathrm{RC}$ frame in the transverse direction is developed in OpenSees [19]. The graphical representation of the numerical modeling scheme is presented in Figure 2. Beams and columns of the RC frame are modeled as fiber-section force-based finite length plastic hinge elements $[1,2,5,6]$. The uniaxial stress-strain response of the concrete fibers is modeled using the model by Yassin [20], while the reinforcing steel bars are modeled with an elastoplastic with linear hardening model. Geometric nonlinearity $(P-\Delta)$ are explicitly considered. A strength-based nonlinear zero-length shear spring is considered near the column end offsets to capture potential column shear failures due to infillframe interaction. The details of the shear-spring model implemented are described elsewhere [21].

Infill panels are modeled through equivalent strut macro-models. Among the numerous infill strut macro models available in the literature to model infill panels [22-25], the infill strut models proposed by (1) Sattar and Liel [26], and (2) Burton and Deierlein [27] are adopted and hereafter referred to as SL10 and BD14, respectively. The SL10 is composed of a single diagonal concentric strut. In contrast, the BD14 model consists of a diagonal concentric strut and an off-diagonal strut, the latter connected at the end of the column end offsets. Figure 2(c) shows the two-infill strut model backbone curves, based on expected infill model parameters. The differences in the infill strut backbones arise from the different failure mechanisms considered by each infill strut model and the relative strength of the infill and surrounding RC frame.

To account for uncertainty in infill model constitutive parameters, 200 finite element model (FEM) realizations of the infill strut backbones are generated for each infill model, considering five models to experiment bias ratio parameters for the infill strut backbones as basic random variables, including: (1) bias in peak strength, $V_{\text {cap, model }} / V_{\text {cap,exp }}$, (2) bias in initial stiffness, $K_{e, \text { model }} / K_{e, \text { exp }}$, (3) ratio of experiment measured peak strength to yield strength, $V_{\text {cap,exp }} / V_{y, \exp }$, (4) ratio of experiment measured capping drift to yield drift, $\Delta_{c a p, \exp } / \Delta_{y, \exp }$, and (5) ratio of experiment measured residual strength to peak strength, $V_{r, \text { exp }} / V_{\text {cap,exp }}$. Statistics on model bias are determined based on the approach and results presented in Burton and Deierlein [27] and FEMA 307 [28]. 

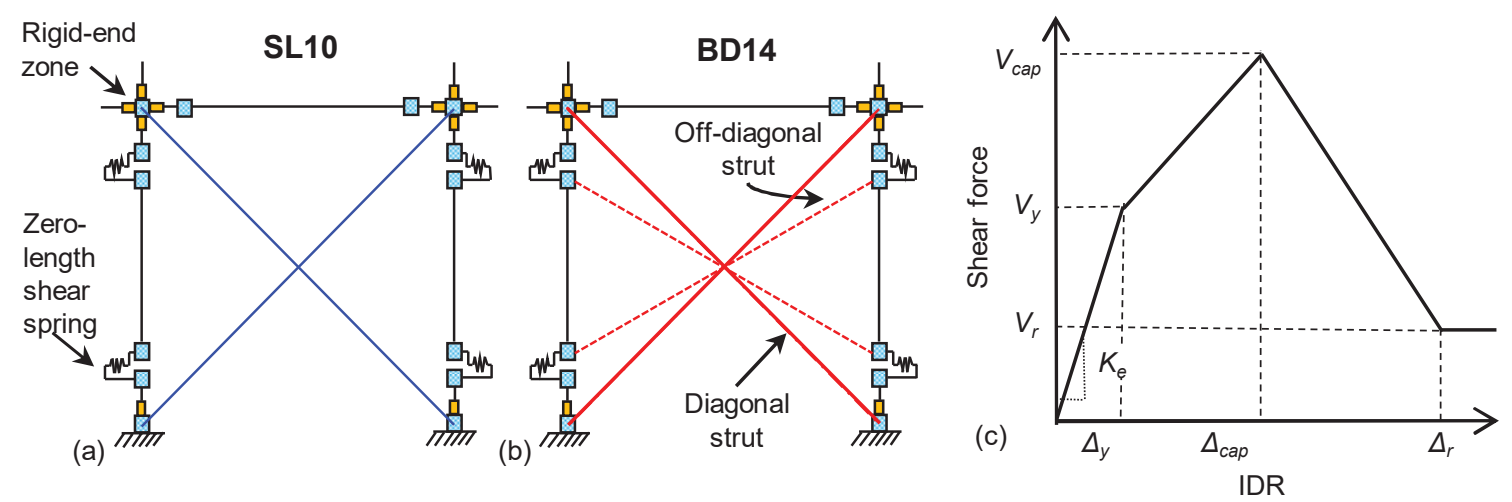

Figure 2: Infilled RC frame modeling: (a) SL10; (b) BD14; (c) infill strut backbone parameters.

\subsection{Structural analysis results}

The uncertainty in ground shaking is considered by simulating nonlinear response history analyses (NRHAs) with 30 natural GM records at eight seismic intensity levels, corresponding to exceedance probabilities of $50 \%, 30 \%, 10 \%, 5 \%, 2 \%$, and $1 \%$ in 50 years, $1 \%$ in 100 years, and $1 \%$ in 200 years, respectively. Within the MSA approach [13], for each seismic hazard level (HL), a different GM records suite is selected for a soil site class D in Salem, Oregon, USA. Two-dimensional structural analyses are performed on the 200 FEM realizations of the two considered model classes representing an internal building $\mathrm{RC}$ frame. The suite of analyses is carried out by using high-performance parallel computing [29].

The summary of the results of NRHAs is presented in Figure 3, in which median profiles for peak interstory drift ratio (PIDR) are reported. It can be seen from Figure 3 that there is a notable reduction of the drift demands at the second and third stories, which are the stories in which the infill panels are located. The comparison between the results for the two model classes indicates a lower PIDR demand in lower stories when the BD14 infill strut model is adopted.
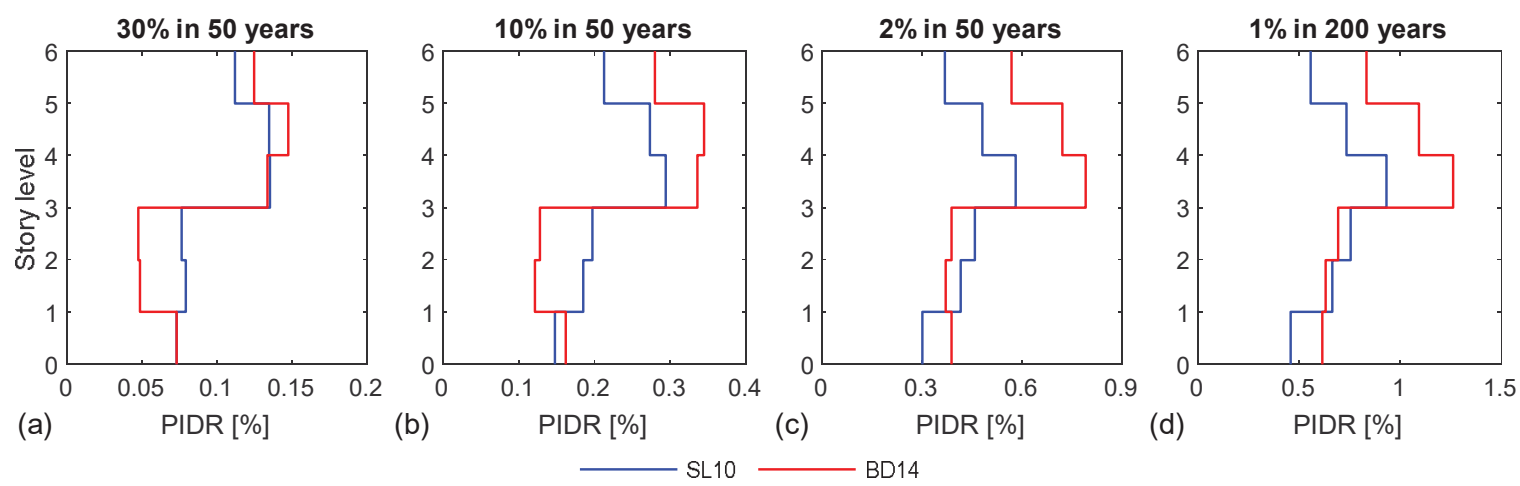

Figure 3: Median PIDR profiles for the two selected model classes, SL10 and BD14, at 30\%, 10\%, 2\% in 50 years HLs and $1 \%$ in 200 years hazard levels.

\section{LOSS ANALYSIS RESULTS}

The building seismic loss analysis is evaluated via the FEMA P-58 loss methodology on a three-dimensional performance model of the building, where the information related to the geometrical building characteristics, the structural response results, as well as the damage and loss description of the elements, is required. In particular, the demand distribution generated from the NRHAs is used as input data for the damage analysis of damageable structural and nonstructural elements at each selected HL. In this paper, the seismic loss analysis is carried out for two building performance models, each one corresponding to one of the two selected infill 
strut model classes. The correspondence is expressed using the specific PIDR demand resulting from the NRHAs of the 200 FEM realizations of that infill strut model class. In other words, the two performance models have a different PIDR distribution, reported in the previous section in Figure 3. In order to appreciate the influence of infill modeling uncertainty, the fragility and loss functions of the structural and nonstructural elements are the same for the two performance models. Figure 4 reports the mean repair cost values at the selected seismic intensities for the two performance models, normalized by the total replacement cost of the building. The element category deaggregation of mean repair cost is also reported. The seismic risk due to collapse is much less relevant than those from element damage analysis, which is partly explained by the fact that a modern code-designed building is considered in this study. The figure shows that the most substantial contribution to the risk is from the masonry infill walls, whereas repair costs from MEP (mechanical, electric, and plumbing) elements are less relevant at higher HLs. In addition, repair costs due to collapse for the BD14 model class become progressively more important with increasing HLs and even though a similar trend is observed for the SL10 model class, the contribution of collapse to the risk is less for the latter model class.

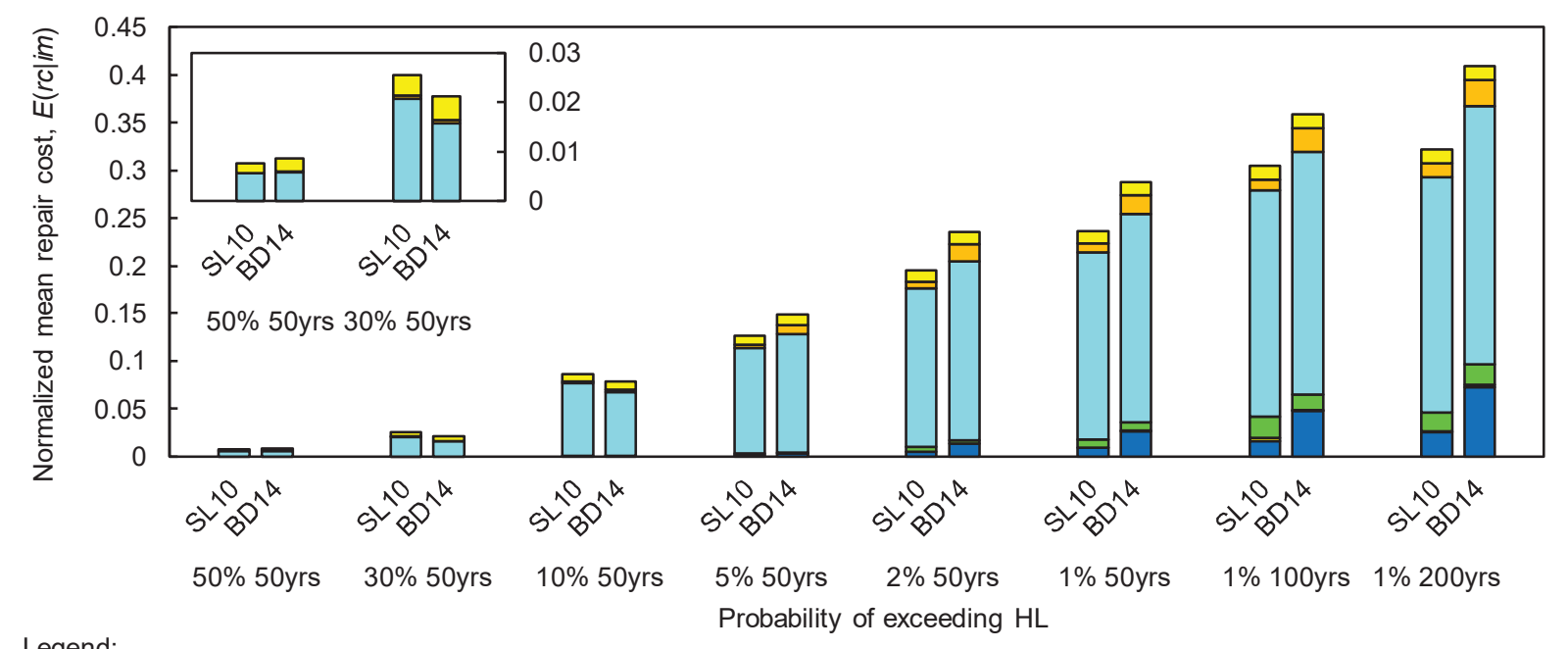

Legend:

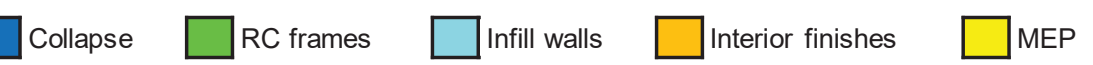

Figure 4: Effect of model class uncertainty on the mean total repair cost, deaggregated by the different structural and nonstructural elements contribution, for the two implemented performance models, SL10 and BD14.

To illustrate the propagation of the uncertainty from the structural response to losses, the dispersions of the maximum PIDR over all the building stories (MIDR), $\beta_{M I D R}$, and repair cost dispersions, $\beta_{R C}$, are compared at the selected HLs. Figure 5 reveals an amplification of repair cost dispersions compared to MIDR dispersions, and results in Figure 5(b) indicate that dispersions of seismic loss in terms of repair costs decrease as seismic intensity increases, probably because higher values of the EDP imply that elements damage condition tend to concentrate at the higher damage states, hence the same for subsequent elements loss. This observation is consistent with the results presented in Kohrangi et al. [30].

Within a more comprehensive seismic loss analysis, the expected annualized losses (EAL) are computed as a percentage of the total replacement cost. The estimated EAL values are very similar, $0.0728 \%$ and $0.0738 \%$ for the SL10 model class and BD14 model class, respectively, revealing a negligible influence of infill strut model class uncertainty on annualized losses for the present case-study modern RC building. Moreover, these values are relatively low when compared with studies on older RC frame buildings [15, 31, 32]. 

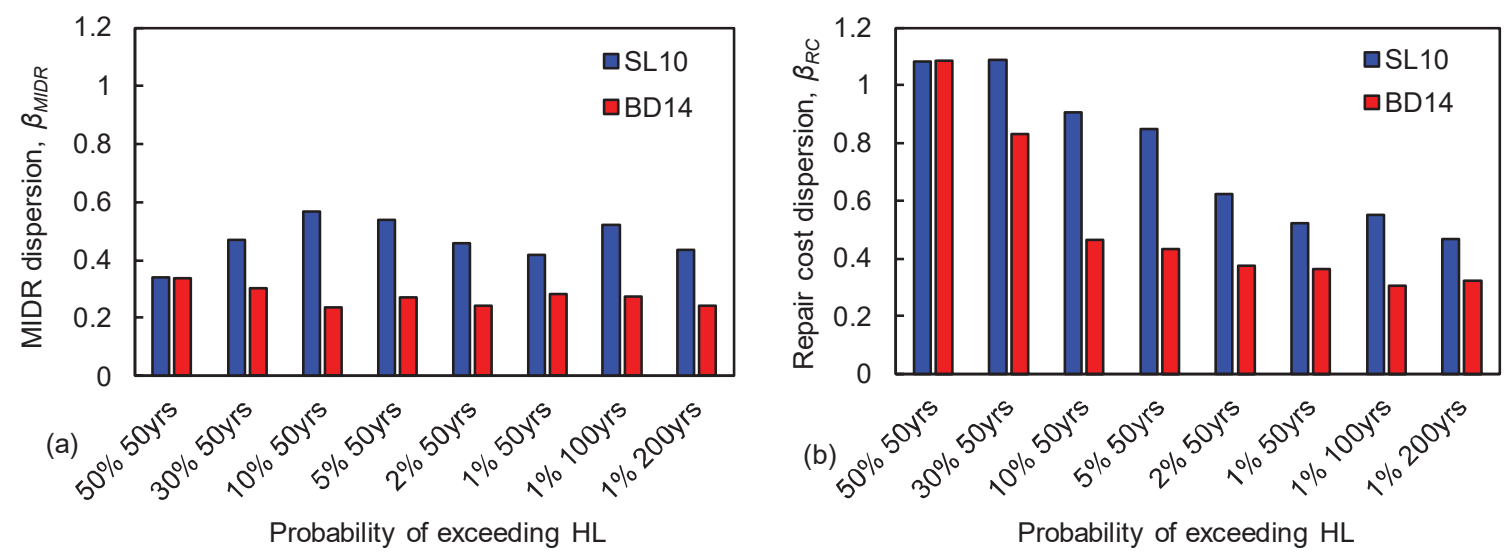

Figure 5: Logarithmic standard deviation for the two implemented performance models, SL10 and BD14: (a) maximum peak inter-story drift ratio, $\beta_{M I D R} ;$ (b) repair cost, $\beta_{R C}$

The EAL percentage deaggregation in terms of replacement losses and damageable element category losses reported in the bar chart in Figure 6 confirms the predominant contribution from masonry infill walls, whereas MEP elements contributed to approximately $15 \%$ of EAL. The structural damage contribution to the risk is negligible, highlighting the importance of using modern building codes to reduce seismic risk.

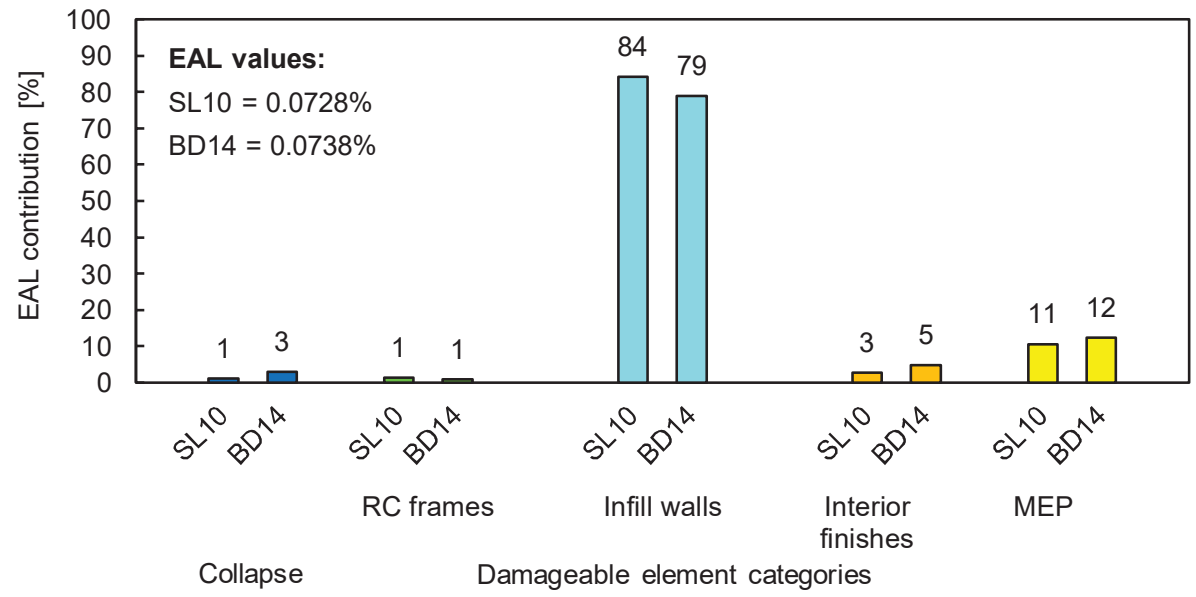

Figure 6: Contributions of collapse and damageable element losses to expected annualized loss for the two implemented performance models, SL10 and BD14.

\section{CONCLUSIONS}

This paper aims to assess the effect of model class uncertainty related to URM infills modeling on seismic risk of a modern RC building by using two different equivalent strut models, namely SL10 and DB14, and the uncertainty in the infill strut backbone parameters. NRHAs were performed at eight hazard levels for 200 FEM realizations of each of the two selected infill strut backbones, obtained through Latin hypercube sampling of the backbone parameters. The key findings of the study are as follows:

- Comparison between uncertainties in NRHAs results and loss analysis results shows a strong amplification of repair cost dispersions compared to maximum PIDR (MIDR) dispersion at low and medium HLs, which reduce at higher HLs, for both the infill-strut model class used. 
- The results of the loss analysis reveal the influence of model class selection for URM walls on mean repair costs; in fact, the SL10 model class experiences larger losses at low and medium HLs, whereas repair costs for the BD14 model class become progressively predominant at increasing HLs due to the higher contribution of collapse losses.

- The EAL values for the two implemented performance models are very similar. Moreover, the EAL deaggregation indicates the predominant contribution from the masonry infill walls and other nonstructural elements, while the contribution from RC frames and collapse is negligible.

Summarizing, model class uncertainty for URM infills has significant effects on repair costs and mostly on repair costs dispersions, whereas the impact on annualized costs is less relevant. Such consideration is valid for the present case-study modern RC building, and further work should be performed to validate the results.

\section{ACKNOWLEDGEMENT}

The first, the third, and the last author wish to acknowledge the financial support received by the Italian Department of Civil Protection (ReLUIS Grant - Reinforced Concrete Structures). The second and fifth authors would like to acknowledge that part of the funding for this study was provided as part of the cooperative agreement 70NANB15H044 between the National Institute of Standards and Technology (NIST) and Colorado State University through a subaward to Oregon State University. The contents expressed in this paper are the views of the authors and do not necessarily represent the opinions or views of NIST or the US Department of Commerce.

\section{REFERENCES}

[1] F.L.A. Ribeiro, L.A.C. Neves, A.R. Barbosa, Implementation and Calibration of FiniteLength Plastic Hinge Elements for Use in Seismic Structural Collapse Analysis. Journal of Earthquake Engineering, 21, 1197-1219, 2017.

[2] H. Varum, R. Dumaru, A. Furtado, A.R. Barbosa, D. Gautam, H. Rodrigues, Seismic Performance of Buildings in Nepal After the Gorkha Earthquake. Impacts and Insights of Gorkha Earthquake in Nepal, Elsevier, 2018.

[3] M. Faggella, R. Gigliotti, G. Mezzacapo, E. Spacone, Graphic dynamic prediction of polarized earthquake incidence response for plan-irregular single story buildings. Bulletin of Earthquake Engineering, 16, 4971-5001, 2018.

[4] A.F. Mohammad, M. Faggella, R. Gigliotti, E. Spacone, Effects of bond-slip and masonry infills interaction on seismic performance of older R/C frame structures. Soil Dynamics and Earthquake Engineering, 109, 251-265, 2018.

[5] F. Romano, M. Zucconi, B. Ferracuti, Seismic fragility curves for RC buildings at territorial scale. Proceedings of the 7th International Conference on Computational Methods in Structural Dynamics and Earthquake Engineering (COMPDYN 2019), Hernosissos, Crete, Greece, June, 24-26, 2019.

[6] M. Zucconi, R. Ferlito, L. Sorrentino, Validation and extension of a statistical usability model for unreinforced masonry buildings with different ground motion intensity measures. Bulletin of Earthquake Engineering, 18, 767-795, 2020. 
[7] H. Crowley, J.J. Bommer, R. Pinho, J. Bird, The impact of epistemic uncertainty on an earthquake loss model. Earthquake Engineering and Structural Dynamics, 34, 1653$1685,2005$.

[8] D. Celarec, P. Ricci, M. Dolšek, The sensitivity of seismic response parameters to the uncertain modelling variables of masonry-infilled reinforced concrete frames. Engineering Structures, 35, 165-177, 2012.

[9] A.F. Mohammad, M. Faggella, R. Gigliotti, E. Spacone, Probabilistic seismic response sensitivity of nonlinear frame bending-shear and infill model parameters for an existing infilled reinforced concrete structure. Proceedings of the twelfth International Conference on Computational Structures Technology, 2014.

[10] A. Muratovic, N. Ademovic, Influence of masonry infill on reinforced concrete frame structures' seismic response. Coupled systems mechanics, 4, 173-189, 2015.

[11] J.L. Beck, K.-V. Yuen, Model Selection Using Response Measurements: Bayesian Probabilistic Approach. Journal of Engineering Mechanics, 130, 192-203, 2004.

[12] B.A. Bradley, A critical examination of seismic response uncertainty analysis in earthquake engineering. Earthquake Engineering \& Structural Dynamics, 42, 1717 1729, 2013.

[13] F. Jalayer, Direct probabilistic seismic analysis: implementing non-linear dynamic assessments. Department of Civil and Environmental Engineering, Stanford University, 2003.

[14] FEMA, FEMA P-58-1: Seismic performance assessment of buildings - Methodology. Federal Emergency Management Agency, 2012.

[15] F. Romano, M. Faggella, R. Gigliotti, M. Zucconi, B. Ferracuti, Comparative seismic loss analysis of an existing non-ductile RC building based on element fragility functions proposals. Engineering Structures, 177, 707-723, 2018.

[16] C. Del Vecchio, M. Di Ludovico, S. Pampanin, A. Prota, Repair Costs of Existing RC Buildings Damaged by the L'Aquila Earthquake and Comparison with FEMA P-58 Predictions. Earthquake Spectra, 34, 237-263, 2018.

[17] D. Cook, K. Wade, C. Haselton, J. Baker, D.J. Debock, A structural response prediction engine to support advanced seismic risk assessment. Proceedings of the 11th U.S. National Conference on Earthquake Engineering, Los Angeles, California, June 25-29, 2018.

[18] F. Romano, M.S. Alam, M. Zucconi, M. Faggella, A.R. Barbosa, B. Ferracuti, Seismic demand model class uncertainty in seismic loss analysis for a code-designed URM infilled RC frame building. Bulletin of Earthquake Engineering, 19, 429-462, 2021.

[19] F. McKenna, M.H. Scott, G.L. Fenves, Nonlinear Finite-Element Analysis Software Architecture Using Object Composition. Journal of Computing in Civil Engineering, 24, 95-107, 2010.

[20] M.H.M. Yassin, Nonlinear analysis of prestressed concrete structures under monotonic and cyclic loads. University of California, Berkeley, 1994.

[21] M.S. Alam, A.R. Barbosa, Probabilistic seismic demand assessment accounting for finite element model class uncertainty: Application to a code-designed URM infilled reinforced concrete frame building. Earthquake Engineering \& Structural Dynamics, 
47, 2901-2920, 2018.

[22] M.N. Fardis, Experimental and numerical investigations on the seismic response of RC infilled frames and recommendations for code provisions. Report ECOEST-PREC8 No. $6,1996$.

[23] W.W. El-Dakhakhni, M. Elgaaly, A.A. Hamid, Three-Strut Model for Concrete Masonry-Infilled Steel Frames. Journal of Structural Engineering, 129, 177-185, 2003.

[24] F.J. Crisafulli, A.J. Carr, Proposed Macro-Model for the Analysis of Infilled Frame Structures. Bulletin of the New Zealand Society for Earthquake Engineering, 40, 6977, 2007.

[25] A. Stavridis, Analytical and experimental study of seismic performance of reinforced concrete frames infilled with masonry walls. University of California, San Diego, 2009.

[26] S. Sattar, A.B. Liel, Seismic performance of reinforced concrete frame structures with and without infill walls. 9th US National and 10th Canadian Conference on Earthquake Engineering, Toronto, Canada, 2010.

[27] H. Burton, G. Deierlein, Simulation of Seismic Collapse in Nonductile Reinforced Concrete Frame Buildings with Masonry Infills. Journal of Structural Engineering, 140, A4014016, 2014.

[28] FEMA, FEMA 307: Evaluation of earthquake damaged concrete and masonry wall buildings - technical resources. Federal Emergency Management Agency, 1998.

[29] M. Faggella, A. Barbosa, J.P. Conte, E. Spacone, J.I. Restrepo, Seismic Assessment of R/C Building Structure through Nonlinear Probabilistic Analysis with Highperformance Computing. AIP Conference Proceedings, AIP, 2008.

[30] M. Kohrangi, D. Vamvatsikos, P. Bazzurro, Implications of Intensity Measure selection for seismic loss assessment of 3-D buildings. Earthquake Spectra, 32, 2167 2189, 2016.

[31] C.B. Haselton, C.A. Goulet, J. Mitrani-reiser, J.L. Beck, G.G. Deierlein, K.A. Porter, J.P. Stewart, An Assessment to Benchmark the Seismic Performance of a CodeConforming Reinforced Concrete Moment-Frame Building. 2008.

[32] C.M. Ramirez, E. Miranda, Building-specific loss estimation methods \& tools for simplified performance-based earthquake engineering. The John A. Blume Earthquake Engineering Center Department of Civil and Environmental Engineering Stanford University, 2009. 